\title{
USO DE SEMENTES COM TRATAMENTO BIOLÓGICO NO CRESCIMENTO DE BRACHIARIA
}

\author{
Ana Carolina Marinho Leme ${ }^{1}$; Rita de Cássia Lima Mazzuchelli ${ }^{2}$; Fabio Fernando de Araujo ${ }^{2}$ \\ ${ }^{1}$ Engenheira Agrônoma. ${ }^{2}$ Universidade do Oeste Paulista - UNOESTE, Programa de Pós Graduação em Agronomia, \\ Presidente Prudente -SP. E-mail: carolina mleme@hotmail.com; ritamazzuchelli@yahoo.com.br
}

\section{RESUMO}

O objetivo do presente trabalho foi avaliar o efeito do tratamento biológico com Bacillus subtilis em sementes de Brachiaria, avaliando a emergência e crescimento das plantas em casa de vegetação. $O$ delineamento experimental foi inteiramente casualizado com seis tratamentos, cinco repetições, totalizando 30 parcelas experimentais. Sendo estabelecidos os seguintes tratamentos: testemunha; priming; biopriming; revestimento com Bacillus subtilis; revestimento sem Bacillus subtilis e inoculação direta de Bacillus subtilis no sulco de plantio. A pesquisa foi realizada em casa de vegetação onde foram distribuídas 50 sementes por repetição em vasos. Após 20 dias do plantio foi realizada a análise de emergência e dez plantas de cada parcela experimental foram retiradas para análises de biomassa seca. Aos 47 dias após o plantio as plantas foram cortadas respeitando a gema apical para determinação da massa seca da parte aérea e altura de plantas. $A$ utilização da inoculação de Bacillus subtilis já no sulco de semeadura, possibilitou maior germinação de Brachiaria brizantha cv. Marandú. O tratamento "bio-priming" resultou em maior desenvolvimento das raízes, parte aérea e matéria seca nas plantas de Brachiaria brizantha cv. Marandú.

Palavras-chave: Bacillus subtilis, Gramíneas, Tratamento de semente.

\section{USE OF SEEDS WITH BIOLOGICAL TREATMENT ON BRACHIARIA GROWTH}

\begin{abstract}
The objective of this study was to evaluate the effect of biological organic coating with Bacillus subtilis in Brachiaria, assessing the emergence and growth of plants in the greenhouse. The experimental design was completely randomized with six treatments, five replicates, totalizing 30 experimental plots. The following treatments was established: control; priming; biopriming; coating with Bacillus subtilis; coating without Bacillus subtilis and direct inoculation of Bacillus subtilis at sowing. The research was conducted in a greenhouse where 50 seeds were distributed by repetition in pots. After 20 days from sowing to emergence, it was analysing ten plants of each plot to achieve dry biomass. At 47 days after sowing the plants were cut keeping the apical meristem to determine the dry mass of the shoot and plant height. The use of direct inoculation of Bacillus subtilis at sowing allowed higher germination of Brachiaria brizantha. Marandú. The biopriming treatment resulted in higher root development, shoot and dry matter in plants of Brachiaria brizantha cv. Marandú.
\end{abstract}

Keywords: Bacillus subtilis, grasses, seed treatment. 


\section{INTRODUÇÃO}

O uso de sementes de boa qualidade é essencial para o sucesso da semeadura, estando diretamente relacionadas à produtividade e lucratividade obtidas (SALUM et al., 2008).

O recobrimento ou peletização de sementes consiste num mecanismo de aplicação de materiais inertes e adesivos, com o objetivo de aumentar o tamanho da semente, bem como modificar sua forma e textura para facilitar sua distribuição e manuseio, especialmente àquelas muito pequenas, pilosas, rugosas ou deformadas (SILVA et al., 2002). O objetivo principal do recobrimento é melhorar a semeadura da semente (SAMPAIO; SAMPAIO, 1994).

Quando a peletização é associada ao tratamento com fungicidas e inseticidas, ela pode contribuir para o estabelecimento adequado das plantas no campo (BAUDET; PERES, 2004). Esta técnica tem como principal vantagem, um melhor desempenho quando comparadas às sementes nuas (MEDEIROS et al., 2006), bem como a possibilidade de incorporar nutrientes e demais produtos fitossanitários (SILVA et al., 2002).

O controle biológico por microrganismos atua como alternativa inteligente para reduzir ou eliminar o uso de agroquímicos no controle de fitopatógenos. A diversidade de microrganismos, bem como suas relações antagônicas, surgem como ferramentas importantes para o controle biológico aplicado. Particularmente para bactérias, muitos trabalhos vêm sendo realizados para elucidar as interações entre antagonista-patógeno-hospedeiro (ROMEIRO et al., 2005; HALFELDVIEIRA et al., 2006; RAO et al., 2009).

A bactéria Bacillus subtilis é um excelente agente de biocontrole, podendo ser encontrada como PGPR (rizobactérias promotoras de crescimento em plantas), bactérias epifíticas e endofíticas (GUPTA et al., 2000). Dessa forma, a bactéria Bacillus subtilis, tem sido usada comercialmente para o biocontrole de enfermidades de plantas, bem como para aumentar a produtividade das culturas (NGUGIA et al., 2005).

O objetivo do presente trabalho foi avaliar o efeito do tratamento biológico com Bacillus subtilis em sementes de Brachiaria brizantha cv. Marandú, avaliando o desenvolvimento e produtividade das plantas em casa de vegetação.

\section{METODOLOGIA}

O estudo foi realizado no Laboratório de Microbiologia e em casa de vegetação, na Faculdade de Ciências Agrárias da Universidade do Oeste Paulista - UNOESTE, nos meses de março a maio de 2014. O clima da região é pela classificação de Köppen Aw como mesotérmico 
com verões quentes e período chuvoso bem definido nos meses de setembro a março e invernos secos com temperaturas mais amenas nos meses de abril a setembro.

Foram utilizadas sementes sem escarificação de Brachiaria brizantha (Hochst ex A. Rich.) Stapf. cultivar Marandú. As sementes utilizadas foram caracterizadas inicialmente obtendo $94 \%$ de pureza e $96 \%$ de sementes viáveis no teste do tetrazólio.

O delineamento experimental foi inteiramente casualizado com seis tratamentos, 5 repetições, totalizando 30 parcelas experimentais. Sendo estabelecidos os seguintes tratamentos: testemunha; priming; biopriming; peletização com Bacillus subtilis; peletização sem Bacillus subtilis e inoculação direta de Bacillus subtilis no sulco de semeadura. Para cada tratamento foram utilizados 183 gramas de sementes.

Para execução do tratamento Priming, $183 \mathrm{~g}$ de sementes foram colocadas em $10 \mathrm{~mL}$ de água salina estéril e mantidas em agitação a 120 rpm por um período de 24 horas e em seguida as sementes foram destinadas à secagem por um período de 24 horas em temperatura ambiente (ARAUJO; GUABERTO; SILVA, 2012).

Foi utilizada a estirpe de Bacillus subtilis (AP-3) para a execução do Biopriming. A suspensão bacteriana foi ajustada para a concentração de $1,0 \times 10^{8}$ unidades formadoras de colônia (ufc) por $\mathrm{mL}$. Foi realizado o tratamento de $183 \mathrm{~g}$ de sementes de braquiária utilizando-se $45,82 \mathrm{~mL}$ de suspensão de células em solução salina que foram misturadas em tambor rotativo à 120 rpm por um período de 24 horas em seguida destinado a secagem em temperatura ambiente por 24 horas.

Para a constituição do tratamento de peletização, foi dissolvido em $45,82 \mathrm{~mL}$ de água destilada, 1,5\% de methylcelulose e essa solução foi adicionada a $183 \mathrm{~g}$ de sementes. Para a secagem do líquido remanescente $73,2 \mathrm{~g}$ de talco (silicato de magnésio) foi adicionado até uniformidade do revestimento nas sementes que em seguida receberam secagem em temperatura ambiente por um período de 24 horas.

Para a efetivação do tratamento com revestimento com Bacillus subtilis, $1,5 \%$ de methylcelulose foi diluída em $45,82 \mathrm{~mL}$ de solução contendo a bactéria e em seguida foi adicionado $22,9 \mathrm{~mL}$ de água destilada. Para a secagem do líquido remanescente, foi adicionado $100 \mathrm{~g}$ de talco (silicato de magnésio) de forma que as sementes ficassem uniformes, e em seguida foram destinadas a secagem em temperatura ambiente por 24 horas. No momento da semeadura foi realizado um tratamento com inoculação de células de Bacillus subtilis (concentração 1,0 $\mathrm{x}$ $\left.10^{8}\right)$, diretamente no sulco de semeadura, sobre as sementes. 
Foi conduzido um tratamento controle, sem a aplicação de qualquer material nas sementes.

As repetições foram feitas com 50 sementes por repetição, distribuídas uniformemente em 5 linhas (14 sementes na linha central; 10 sementes nas duas linhas laterais à linha central e por último 8 sementes nas duas linhas mais externas) de cada vaso.

As sementes remanescentes foram acondicionadas em embalagens de papel e armazenadas em condições de temperatura e umidade ambientes.

Foi avaliada a taxa de emergência das sementes, após 20 dias da semeadura, contando o número de sementes emerças por vaso. No mesmo dia foram retiradas 10 plantas de cada vaso, para análises de comprimento da parte aérea e sistema radicular, massa seca da parte aérea e sistema radicular. Para determinação da massa seca, as plantas foram acondicionadas em sacos de papel Kraft, colocadas em estufa com circulação forçada de ar a $60^{\circ} \mathrm{C}$, até atingirem massa constante. Após foram encaminhadas para balança analítica de precisão para análise da massa seca.

Aos 47 dias após o plantio foi realizado um corte, ao nível de $3 \mathrm{~cm}$ do solo, respeitando a gema apical para promover o rebrote, a parte aérea foi aferida com régua, para determinação da parte aérea, sendo posteriormente acondicionadas em sacos de papel Kraft, colocadas em estufa com circulação forçada de ar a $60^{\circ} \mathrm{C}$, até atingirem massa constante.

Os resultados obtidos foram submetidos à análise de variância, através do programa computacional Sistema de Análise de Variâncias - SISVAR (FERREIRA, 2000), sendo as médias comparadas pelo teste Tukey.

\section{RESULTADOS}

Aos 20 dias após o plantio, foi realizada a contagem da emergência das sementes de todos os tratamentos chegando às médias apresentadas na Tabela 1. A maior porcentagem de germinação foi do tratamento em que as sementes receberam a bactéria Bacillus subtilis diretamente no sulco, no momento do plantio (90,5\%). Em seguida, os menores índices de germinação foram, respectivamente, o tratamento controle com um índice de 79\% e o Biopriming com $76 \%$, e quando se utilizou a peletização, com um índice de germinação de $71,5 \%$ 70\% com e sem a bactéria, respectivamente. 
Tabela 1. Porcentagem das plantas de Brachiaria brizantha submetidas a tratamentos nas sementes que emergiram aos 20 dias após a semeadura.

\begin{tabular}{lc}
\hline Tratamentos & Emergência (\%) \\
\hline Peletização & $70,00 \mathrm{c}$ \\
Peletização com B. subtilis & $71,50 \mathrm{c}$ \\
Biopriming & $76,00 \mathrm{bc}$ \\
Controle & $79,00 \mathrm{bc}$ \\
Priming & $81,00 \mathrm{~b}$ \\
Inoculação direta & $90,50 \mathrm{a}$ \\
\hline CV (\%) & 5,25 \\
\hline
\end{tabular}

Médias seguidas de mesma letra não diferem estatisticamente pelo teste Tukey (1\%).

As amostras retiradas aos 20 dias após o plantio mostram que ao ser analisado o desenvolvimento da parte aérea das plantas coletadas, foi possível observar que todos os tratamentos diferem do tratamento controle (Tabela 2). Em relação ao tratamento controle, o biopriming ocasionou um aumento no comprimento da parte aérea das plantas em $47,5 \%$, seguido da peletização sem a bactéria $B$. subtilis onde o valor foi de $38,7 \%$; a Inoculação da bactéria diretamente da semente teve aumento de $32,8 \%$; o priming foi de $31,37 \%$ e a peletização com a bactéria proporcionou aumento de $27,6 \%$, desta forma todos os tratamentos realizados apresentaram maior desenvolvimento em relação ao controle.

Com relação ao comprimento das raízes das plantas, as amostras indicaram que o tratamento Biopriming foi o único que diferiu significativamente do tratamento controle, aumentando o comprimento das raízes em 33,01\%. Os demais tratamentos não apresentaram diferença significativa em relação ao tratamento controle (Tabela 2).

Através da análise de massa seca da parte aérea é possível observar que apenas o tratamento biopriming aumentou significativamente o peso das plantas em $50,2 \%$ em relação ao controle. (Tabela 2). 
Tabela 2. Comprimento da parte aérea (C.P.A. em centímetros) e comprimento do sistema radicular (C.S.R. em centímetros) das plantas de Brachiaria brizantha submetidas a tratamentos nas sementes, aos 20 dias após a semeadura.

\begin{tabular}{lccl}
\hline Tratamentos & C.P.A. & C.S.R. & M.S.P.A. \\
\hline Controle & $8,85 \mathrm{~b}$ & $5,18 \mathrm{c}$ & $0,173 \mathrm{c}$ \\
Peletização com B. subtilis & $11,30 \mathrm{a}$ & $6,75 \mathrm{ab}$ & $0,234 \mathrm{ab}$ \\
Priming & $11,62 \mathrm{a}$ & $6,22 \mathrm{abc}$ & $0,224 \mathrm{abc}$ \\
Inoculação direta & $11,76 \mathrm{a}$ & $5,38 \mathrm{bc}$ & $0,200 \mathrm{bc}$ \\
Peletização & $12,28 \mathrm{a}$ & $6,30 \mathrm{abc}$ & $0,248 \mathrm{ab}$ \\
Biopriming & $13,06 \mathrm{a}$ & $6,89 \mathrm{a}$ & $0,260 \mathrm{a}$ \\
\hline CV (\%) & 8,70 & 12,09 & 11,79 \\
\hline
\end{tabular}

Médias seguidas de mesma letra não diferem estatisticamente pelo teste Tukey (1\%).

Aos 47 dias após o plantio das sementes, foi feito o desbaste de todas as plantas, deixando apenas dez plantas por vaso, as suas partes aéreas foram cortadas a uma distância de três centímetros do solo. Através das medidas da parte aérea das plantas, pode ser observado que o tratamento biopriming ocasionou um aumento no comprimento da parte aérea em $70,3 \%$ e o tratamento de Peletização sem a bactéria aumentou o comprimento em 32,8\% (Tabela 3), ou seja, ambos os tratamentos diferiram significativamente do tratamento controle.

Em seguida, os maiores índices de matéria seca, foram respectivamente, dos tratamentos: Priming (75\%), Peletização (50\%) e Inoculação diretamente nas sementes no momento do plantio (20\%).

Tabela 3. Altura das plantas (em centímetros) e massa seca da parte aérea (M.S.P.A. em gramas) aos 47 dias após o plantio, de Brachiaria brizantha submetidas a tratamentos nas sementes, após o corte respeitando a gema apical.

\begin{tabular}{lcc}
\hline Tratamentos & Altura & M.S.P.A. \\
\hline Testemunha & $12,80 \mathrm{c}$ & $0,0396 \mathrm{c}$ \\
Inoculação direta & $16,00 \mathrm{bc}$ & $0,0476 \mathrm{bc}$ \\
Peletização & $17,00 \mathrm{~b}$ & $0,0594 \mathrm{bc}$ \\
Priming & $19,00 \mathrm{ab}$ & $0,0694 \mathrm{~b}$ \\
Peletização com B. subtilis & $19,60 \mathrm{ab}$ & $0,0756 \mathrm{ab}$ \\
Biopriming & $21,80 \mathrm{a}$ & $0,0990 \mathrm{a}$ \\
\hline CV (\%) & 11,81 & 22,58 \\
\hline
\end{tabular}

Médias seguidas de mesma letra não diferem estatisticamente pelo teste Tukey (1\%). 


\section{DISCUSSÃO}

Segundo Duran (1998), as sementes "primerizadas" tem maior atividade metabólica o que justifica um melhor desempenho em campo, sendo o tratamento priming, o segundo melhor tratamento em relação à avaliação de emergência do experimento, com 81\%.

De acordo com Callan et al. (1990), a utilização do tratamento biopriming aumenta a capacidade da planta quando submetidas à condições de estresse, além de protegê-la de condições adversas.

Ainda de acordo com Reddy (2013), a técnica de biopriming (inoculação com organismos benéficos para proteger a semente) é recente e integra aspectos biológicos e fisiológicos (hidratação das sementes) participa do controle de doenças, sendo utilizado como um método alternativo para o controle de muitos patógenos de solo, podendo substituir o controle químico.

Portanto, a utilização da técnica de biopriming pode proteger a planta contra patógenos de solo, Rao et al. (2009) avaliando biopriming com inoculação de Pseudomonas fluorescens, verificou sua utilização como potencial para controle do fungo Alternaria blight. O biopriming, uma combinação de tratamento biológico de sementes e hidratação pré-plantio (CALLAN et al., 1990), é uma estratégia para melhorar a confiança de tratamentos biológicos.

Sung e Chang (1993) observaram melhorias devido ao biopriming de sementes de girassol, que pode ser devido às mudanças quantitativas induzidas pelo priming no conteúdo bioquímico das sementes e melhoria na integridade das membranas, podendo também ser devido à proliferação do bioagente $P$. fluorescens. Callan et al. (1990) também estabeleceu que o agente de biocontrole bacteriano pode se multiplicar substancialmente na semente durante o biopriming.

\section{CONCLUSÃO}

A utilização da inoculação de Bacillus subtilis nas sementes já no sulco de semeadura, possibilitou maior emergência de Brachiaria brizantha cv. Marandú.

O tratamento biopriming resultou em maior desenvolvimento das raízes, parte aérea e matéria seca nas plantas de Brachiaria brizantha cv. Marandú.

\section{REFERÊNCIAS}

ARAUJO, F. F.; GUABERTO, L. M.; SILVA, I. F. Bioprospeç̧ão de rizobactérias promotoras de crescimento em Brachiaria brizantha. Revista Brasileira de Zootecnia, v. 41, n. 3, p. 521-527, 2012. http://dx.doi.org/10.1590/S1516-35982012000300007

BAUDET, L.; PERES, W. Recobrimento de sementes. Seed News, v.8, n.1, p.20-23, 2004. 
CALLAN, N. W.; MATHRE, D. E; MILLER, J. B. Bio-priming seed treatment for biological control of Pythium ultimum pre emergence damping off in sh2 sweet corn. Plant Disease v. 74, p. 368-372. 1990. http://dx.doi.org/10.1094/PD-74-0368

DURAN, J.M. Acondicionamento e revestimento de sementes. In: Seminário Panamericano de Sementes, 15, Gramado, 1998. Resumos. Gramado: CESM/RS e FELAS, 1998. p.107-115.

FERREIRA, D. F. Análise estatística por meio do SISVAR (Sistema para Análise de Variância) para Windows versão 4.0. In: Reunião anual da Região Brasileira Da Sociedade Internacional de Biometria, 45., 2000, São Carlos. Anais... São Carlos: UFSCar, p. 255-258. 2000.

GUPTA, V.P.; BOCHOW, H.; DOLEJ, S.; FISCHER, I. Plant growth-promoting Bacillus subtilis strain as potential inducer of systemic resistance in tomato against Fusarium wilt. Zeitschrift für Pflanzenkrankheiten und Pflanzenschutz, v.107, p.145-154, 2000.

HALFELD-VIEIRA, B.A.; VIEIRA, J.R.; ROMEIRO, R.S.; SILVA, H.S.A.; BARACAT-PEREIRA, M.C. Induction os systemic resistance in tomato by the autochthonous phyllopane residente Bacillus cereus. Pesquisa Agropecuária Brasileira, v.41, p.1247-1252, 2006.

http://dx.doi.org/10.1590/S0100-204X2006000800006

MEDEIROS, E.M. et al. Recobrimento de sementes de cenoura com aglomerante em diversas proporções e fungicida. Revista Brasileira de Sementes, v.28, n.3, p.194-100, 2006. http://dx.doi.org/10.1590/S0101-31222006000300014

NGUGIA, H.K.; DEDEJB, S.; DELAPLANEB, K.S.; SAVELLEA, A.T.; SCHERMA, H. Effect of flowerapplied Serenade biofungicide (Bacillus subtilis) on pollination-related variables in rabbiteye blueberry. Biological Control, v.33, p.32-38, 2005.

http://dx.doi.org/10.1016/i.biocontrol.2005.01.002

SALUM, J.D. et al. Características químicas e fisiológicas de sementes de feijão em função do teor de fósforo na semente e doses de fósforo no solo. Revista Brasileira de Sementes, v.30, n.1, 2008. http://dx.doi.org/10.1590/S0101-31222008000100018

SAMPAIO, T.; SAMPAIO, N. Recobrimento de Sementes. Informativo ABRATES. Londrina, v.4, n.3, p.20-52, 1994.

SILVA, J.B.C.; SANTOS, P.E.C; NASCIMENTO, W.M. Desempenho de sementes peletizadas de alface em função do material cimentante e da temperatura de secagem dos péletes. Horticultura Brasileira, Brasília, v.20, n.1, p. 67-70, p. 335-341, 2002.

SUNG, F.J.; CHANG, Y.H.. Biochemical activities associated with priming of sweet corn seeds to improve vigour. Seed Sci. and Technology, n. 21, p. 97-105, 1993.

RAO, M. S. L.; KULKARNI, S.; LINGARAJU, S.; NADAF, H. L. Bio-priming of seeds: apotential tool in the integrated management of Alternaria blight of sunflower. Helia, 32, Nr. 50, p.107-114. 2009. http://dx.doi.org/10.2298/HEL0950107R

REDDY, P. Parvatha. Bio-priming of Seeds. In: Recent advances in crop protection. Springer India, p. 83-90. 2013. http://dx.doi.org/10.1007/978-81-322-0723-8 
ROMEIRO, R.S.; LANNA-FILHO, R.; VIEIRA, J.R.; SILVA, H.S.A.; BARACAT-PEREIRA, M.C.; CARVALHO, M.G. Macromolecules released by a plant growth-promoting rhizobacterium as elicitors of systemic resistance in tomato to bacterial and fungal pathogens. Journal of Phytopathology, v.153, p.120-123. 2005. http://dx.doi.org/10.1111/j.1439-0434.2005.00941.x 